\title{
Hard Mask Process Using Chemically Amplified 157-nm Resists
}

\author{
Takamitsu Furukawa, Seiro Miyoshi, Hiroyuki Watanabe, Sigeo Irie, and Toshiro Itani
}

\author{
Advanced Technology Research Dept. \\ Semiconductor Leading Edge Technologies, Inc. (Selete) \\ 292 Yoshida-cho, Totuska-ku, Yokohoma, 244-0817, Japan \\ E-mail: furukawa2@selete.co.jp
}

\begin{abstract}
We describe and evaluate a pattern transfer process suitable for 157-nm lithography. It consists of a hard mask (HM) process using an organic bottom anti-reflective coating (BARC) / SiN structure. The underlayer of the resist works well as an anti-reflection layer. We obtained a rectangular resist profile using three fluorine-containing resists and a 157-nm microstepper. One of the resists was a side-chain fluorinated resist and the others were main-chain fluorinated resists. The reactive ion etching (RIE) conditions were optimized to obtain a vertical HM profile and minimum critical dimension (CD) shift. Although the resist patterns could be transferred to $\mathrm{SiN}(70 \mathrm{~nm}) \mathrm{HM}$ using any of the resists, the remaining resist thickness was insufficient for mass-production of semiconductor devices. Further improvement of the resist material and optimization of the resist process and etching conditions are necessary. However, using the HM pattern, we were able to fabricate a $\mathrm{WSi} /$ poly-Si $65-\mathrm{nm}$ gate pattern using a high-NA microstepper (NA=0.85), and a tetra-ethyl-orso-silicate (TEOS)-SiO2 150-nm contact hole $(\mathrm{C} / \mathrm{H})$ pattern using a 0.60 -NA microstepper. This clearly demonstrates that our $\mathrm{HM}$ process is the best candidate for sub-70nm-node semiconductor devices.
\end{abstract}

\section{Keywords: 157-nm lithography, fluoropolymer, hard mask, gate and contact hole fabrication}

\section{Introduction}

Optical lithography using an $\mathrm{F}_{2}$ Laser (wavelength $=157 \mathrm{~nm}$ ) is one of the most promising candidates for the mass-production of sub-70nm-node semiconductor devices. The polymers in the conventional resists used for 248-nm or 193-nm lithography readily absorb $157-\mathrm{nm}$ wavelength light [1], so these resists are not applicable to $157-\mathrm{nm}$ lithography. To reduce absorption at the $157-\mathrm{nm}$ wavelength, various fluoropolymers for 157-nm lithography have been developed [2-10], and several resists with small absorption coefficients have shown fairly high resolution [9]. A thin resist is considered necessary for sub-70nm node lithography because the aspect ratio of the resist pattern must be smaller than 3 to prevent the collapse of the pattern [11]. Therefore, the thickness of a $157-\mathrm{nm}$ resist should be less than $200 \mathrm{~nm}$. Although some fluoropolymers showed high reactive ion etching (RIE) durability comparable to that of an ArF resist [10], transferring the pattern to the underlayer is considered much more difficult for 157-nm lithography than for conventional 248-nm or 193-nm lithography. However, there are only a few reports on pattern transfer for 157-nm lithography [12-13].

In this paper, we describe a hard mask (HM) process that is suitable for $157-\mathrm{nm}$ lithography. We have used the process for both gate and contact hole $(\mathrm{C} / \mathrm{H})$ fabrication. We also describe the pattern transfer capabilities of several newly developed fluorine-containing resists.

\section{Experimental}

\subsection{Materials}

Figure 1 shows HM structures for (a) gate and (b) $\mathrm{C} / \mathrm{H}$ fabrication. We used $\mathrm{SiN}$ as the $\mathrm{HM}$ material. The film was deposited on the substrates using chemical vapor deposition (CVD). We used a $\mathrm{WSi}(50 \mathrm{~nm}) /$ poly-Si $(50 \mathrm{~nm}) / \mathrm{SiO}_{2}(100 \mathrm{~nm}) / \mathrm{Si}$ substrate as the gate structure, and a tetra-ethyl-orso-silicate (TEOS)- $\mathrm{SiO}_{2}(500 \mathrm{~nm}) / \mathrm{Si}$ substrate as the $\mathrm{C} / \mathrm{H}$ structure. The thickness of the $\mathrm{HM}$ was adjusted to $70 \mathrm{~nm}$ for gate fabrication and $100 \mathrm{~nm}$ for $\mathrm{C} / \mathrm{H}$ fabrication. We used DUV42 (Brewer Science) as a bottom anti-reflective coating (BARC). Three fluorine-containing resists 


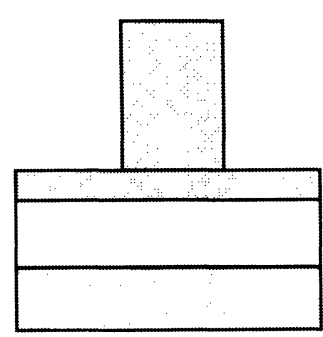

(a) for gate fabrication

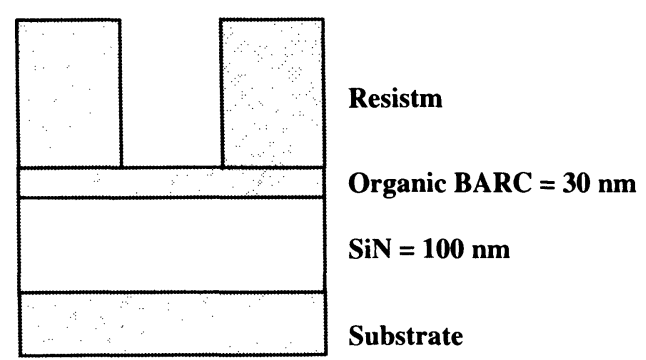

(b) for $\mathrm{C} / \mathrm{H}$ fabrication

Fig. 1. Structures for BARC / SiN hard mask process.

Table 1. Resist properties.

\begin{tabular}{cllccc}
\hline Sample & \multicolumn{1}{c}{ Type } & Base resin & $\begin{array}{c}\text { Absorption } \\
(/ \mu \mathrm{m})\end{array}$ & $\begin{array}{c}\text { Thickness } \\
(\mathrm{nm})\end{array}$ & $\begin{array}{c}\text { Transparency } \\
(\%)\end{array}$ \\
\hline F-resist A & F in side-chain & Silsesquioxane & 3.5 & 120 & 37.7 \\
F-resist B & F in main-chain & TFE / norbornene & 2.1 & 150 & 48.6 \\
F-resist C & F in main-chain & Monocyclic fluorocarbon & 0.8 & 250 & 64.2 \\
KrF-resist & KrF modified & PHS & 6.6 & 80 & 29.8 \\
\hline
\end{tabular}

and a KrF-modified resist were evaluated, as summarized in Table 1. F-resist A is composed of silsesquioxane copolymers with a fluorine element in the side chain. F-resist $\mathrm{B}$ is composed of tetrafluoroethylene (TFE) copolymers with a fluorine in the main chain. F-resist $\mathrm{C}$ is composed of monocyclic fluorocarbon copolymers with a fluorine in the main chain. $\mathrm{KrF}$-resist is composed of poly(hydroxystyrene). Although a thicker resist is desirable for the pattern transfer process, increasing the absorbance of the film is undesirable for resist patterning. The resist thickness of F-resist $\mathrm{A}$, F-resist $\mathrm{B}$, and $\mathrm{KrF}$-resist was adjusted to 120,150 , and $80 \mathrm{~nm}$, respectively, because of their relatively large absorption. The thickness of F-resist $\mathrm{C}$ was adjusted to $250 \mathrm{~nm}$ to prevent pattern collapse.

\subsection{Resist processing}

We used an Ultratech 157-nm microstepper $(\mathrm{NA}=0.60$, illumination $\operatorname{sigma}(\sigma)=0.30)$ and an Exitech 157-nm microstepper $(\mathrm{NA}=0.85, \sigma$ $=0.30$ ) [14]. An alternating phase-shifting mask (alt-PSM) was used for gate fabrication and an attenuated phase-shifting mask (att-PSM, transparency $=5 \%$ ) was used for $\mathrm{C} / \mathrm{H}$ fabrication. The resist films were obtained by spin-casting on anti-reflective substrates and pre-baking at $110-140^{\circ} \mathrm{C}$ for $60-90 \mathrm{sec}$ in an ACT8 coater / developer (TEL). The exposed resists were developed in a TMAH solution using a 20-60 sec puddle process after post-exposure baking at $110-130^{\circ} \mathrm{C}$ for $60-90 \mathrm{sec}$ in a TEL ACT8. The reactive ion etching (RIE) of the BARC / HM, WSi / poly-Si and TEOS-SiO ${ }_{2}$ was done using a Unity II etcher (TEL). Top-down and crosssectional images were obtained using Hitachi S-9300 and S-5000 scanning electron microscopes (SEM), respectively. The optical constants (refractive index $\mathrm{n}$ and extinction coefficient $\mathrm{k}$ ) at the 157-nm wavelength were obtained using a variable-angle spectroscopic micrometer VUV-VASE302 (J. A. Woollam). Lithographic simulations were done using Prolith/3D (KLA Tencor).

\section{Results and Discussion}

\subsection{Lithographic and etching evaluation}

Table 2 summarizes the optical constants of the F-resist A, and HM materials at the 157-nm wavelength. Figure 2(a) shows the calculated reflectivity at the resist / $\mathrm{SiN}$ interface. The high reflectivity was due to the large extinction coefficient of $\mathrm{SiN}$. It was therefore inefficient to attempt to prevent the standing-wave effect when the SiN was $70-n m$ or $100-n m$ thick. However,

Table 2. Optical constants (refractive index $n$, extinction coefficient $k$ ) at 157-nm wavelength.

\begin{tabular}{ccc}
\hline Material & $n$ & $k$ \\
\hline F-resist A & 1.747 & 0.102 \\
DUV42 & 1.674 & 0.227 \\
SiN & 2.079 & 1.085 \\
$\mathrm{Si}$ & 0.662 & 2.031 \\
\hline
\end{tabular}


inserting a thin BARC between the resist and SiN $(70 \mathrm{~nm})$ significantly reduced reflectivity (Fig. 2(b)). The reflectivity was reduced to our target value (less than $2 \%$ ) when the BARC was $30-\mathrm{nm}$ thick. There was no significant difference in reflectivity between an SiN thickness of $70 \mathrm{~nm}$ and $100 \mathrm{~nm}$. BARC also worked to prevent the expected tapered profile often observed at the bottom of a resist fabricated on some inorganic films [15-16]. Therefore, we applied DUV42 (at a thickness of $30 \mathrm{~nm}$ ), which showed good compatibility with F-resist A-C and a relatively high etching rate, as an organic BARC on SiN. For the DUV42 / SiN HM RIE, we applied two sets of RIE conditions: the typical $\mathrm{SiN}$ etching condition (using $\mathrm{CF}_{4} / \mathrm{O}_{2} / \mathrm{CH}_{2} \mathrm{~F}_{2}$ gases), and an optimized condition.

Figure 3(a) shows the 130-85-nm 1:1 line and space $(\mathrm{L} / \mathrm{S})$ pattern of F-resist A delineated using a 0.60-NA microstepper and an alt-PSM in an F-resist A (120 nm) / DUV42 (30 nm) / SiN (70 $\mathrm{nm})$ / $\mathrm{Si}$ structure. F-resist A showed a good imaging performance and a rectangular profile. No

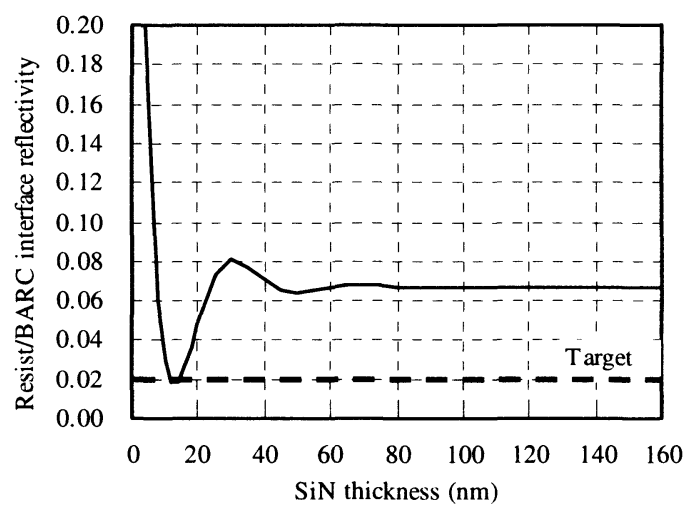

(a) Resist / SiN / Si structure standing wave at the resist sidewall was observed for any of the patterns, demonstrating that the underlayer of the resist sufficiently decreased reflectivity at the resist / BARC interface. Figure 3(b) shows the results of $\mathrm{CF}_{4} / \mathrm{O}_{2} / \mathrm{CH}_{2} \mathrm{~F}_{2}$ RIE. The remaining resist thickness was sufficient after BARC / SiN RIE. However, the SiN patterns showed an obviously tapered profile and there was a large critical dimension (CD) shift during RIE. A vertical profile and a minimum $C D$ shift are needed, especially in gate fabrication. We then optimized the RIE conditions (source gases, power, pressure, etc.). Figure 3(c) shows the results of the optimized RIE, and Figure 4 shows the relative RIE rate of F-resist $\mathrm{A}$, DUV42 and $\mathrm{SiN}$ under the both RIE conditions. Compared to the results obtained under the $\mathrm{CF}_{4} / \mathrm{O}_{2} / \mathrm{CH}_{2} \mathrm{~F}_{2}$ gas condition, the RIE selectivity between the resist and $\mathrm{SiN}$ was low under the optimized condition because of the small amount of CFx deposited on the resist during RIE. However, we obtained a good vertical pattern profile and a smaller CD shift.

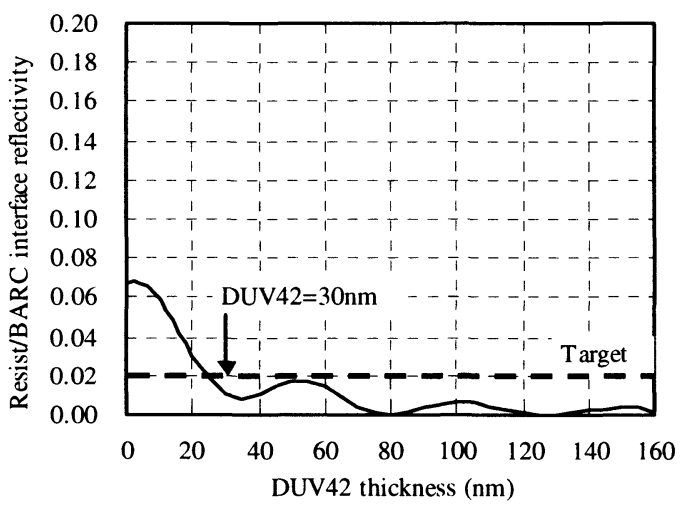

(b) Resist / BARC / SiN (70 nm) / Si

Fig. 2. Calculated reflectivity of $157-\mathrm{nm}$ light at resist/underlayer interface.

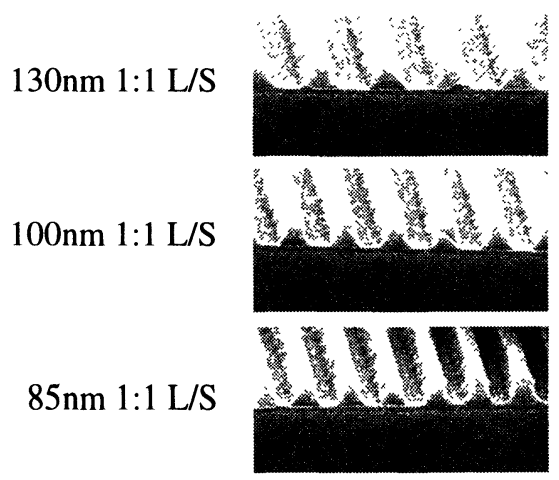

(a)

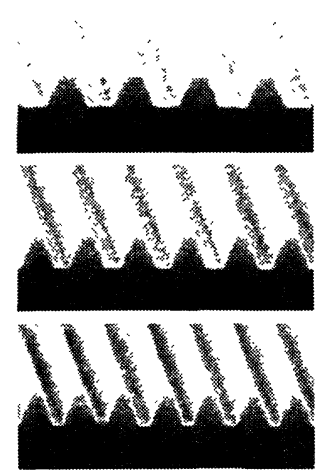

(b)

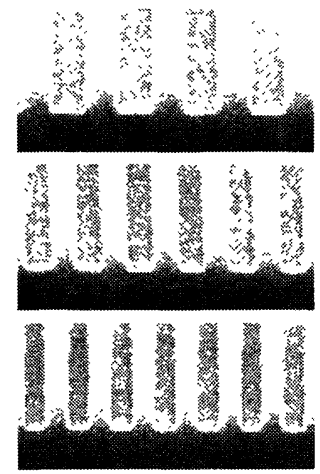

(c)

Fig. 3. Pattern profile of $130 / 100 / 85 \mathrm{~nm}$ 1:1 L/S (a) after development; (b) after DUV42/ SiN RIE for the $\mathrm{CF}_{4} / \mathrm{O}_{2} /$ $\mathrm{CH}_{2} \mathrm{~F}_{2}$ gas condition; and (c) after DUV42 / SiN RIE for the optimized condition. The structure of the film is F-resist A $(120 \mathrm{~nm}) / \mathrm{DUV} 42(30 \mathrm{~nm}) / \mathrm{SiN}(70 \mathrm{~nm}) / \mathrm{Si}$. The exposure tool was a 0.60-NA microstepper using an alt-PSM. 


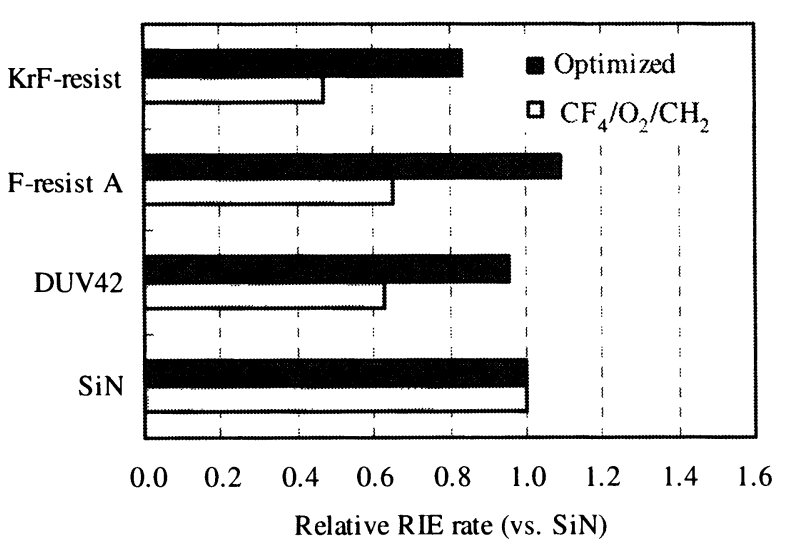

Fig. 4. Relative RIE rate (vs. SiN) under the $\mathrm{CF}_{4} / \mathrm{O}_{2} /$ $\mathrm{CH}_{2} \mathrm{~F}_{2}$ gas condition or optimized RIE condition.

\subsection{Evaluation of fluorine-containing resists}

\subsubsection{RIE durability}

The four resists summarized in Table 1 were applied to the optimized HM RIE conditions. Figure 5 shows the relative RIE rate (versus KrF-resist) of the materials. The relative RIE rate of F-resist A was about 1.3, that of F-resist B was about 1.5, that of F-resist $C$ was about 1.9, and those of both $\mathrm{SiN}$ and BARC were about 1.2.

Figure 6 shows the dependence of the relative RIE rate on the absorption coefficient. The relative RIE rate tended to increase with a decreasing absorption coefficient. The dependence of the relative RIE rate on the fluorine content is shown in Fig. 7. The relative RIE tended to increase with an increase in fluorine content under the optimized RIE condition. These results suggest that RIE durability and the transparency are in conflict with one another.

\subsubsection{Surface roughness}

Figure 8 shows the surface roughness of each resist after the optimized RIE. An ArF-resist (acrylic type) was also observed for reference (shown in Fig. 8(e)). The RIE time was fixed at 10 $\mathrm{sec}$ for all the resists. Slight roughness was observed even on the surface of the KrF-resist. The surface roughness of F-resist A and F-resist B was greater than that of the KrF-resist but less than that of the ArF-resist. Remarkably, the surface roughness of F-resist $\mathrm{C}$ was fairly low.

\subsubsection{Pattern profile}

Figure 9(a) shows 130-nm 1:1 L/S resist patterns delineated using a 0.60-NA microstepper and an

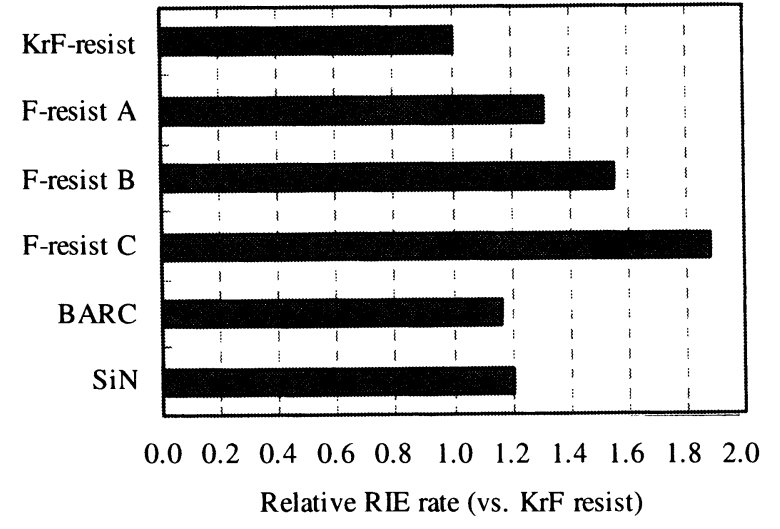

Fig. 5. Relative RIE rate (vs. KrF-resist) of the materials under the optimized RIE condition.

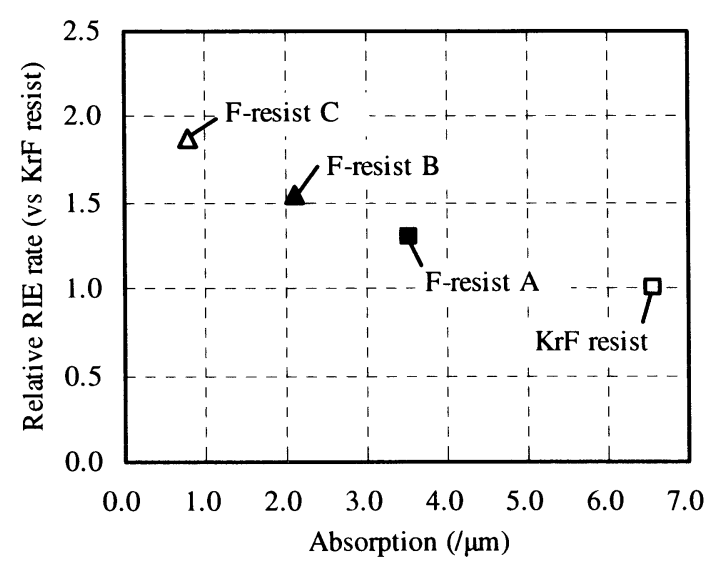

Fig. 6. The dependence of relative RIE rate (vs. KrF-resist) on the absorption constant under the optimized RIE condition.

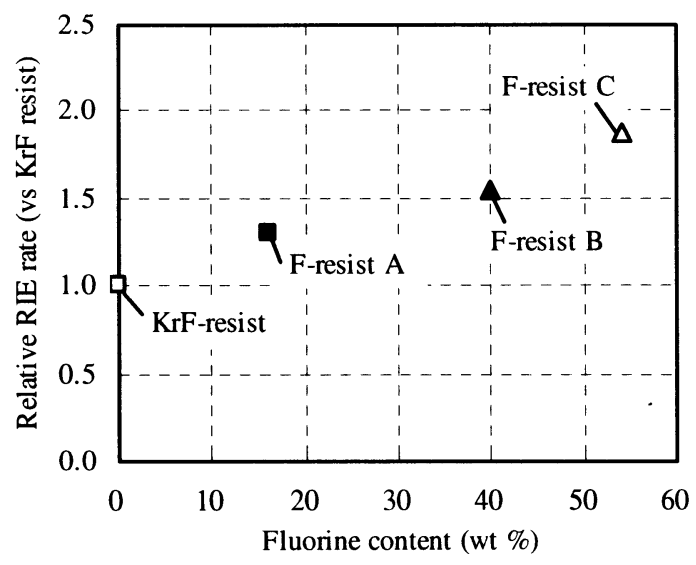

Fig. 7. Dependence of relative RIE rate (vs. KrF-resist) on fluorine content under the optimized RIE condition. 


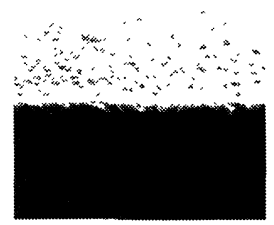

(a) F-resist $\mathrm{A}$

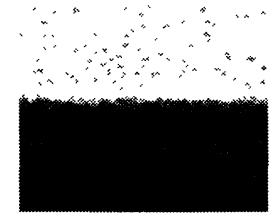

(b) F-resist B

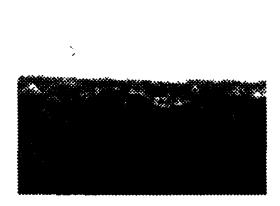

(c) F-resist C

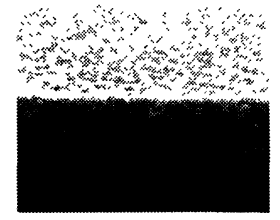

(d) KrF-resist

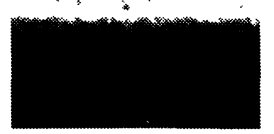

(e) ArF-resist

Fig. 8. Cross-sectional SEM images of resist surface roughness after the optimized RIE.

(a) F-resist A
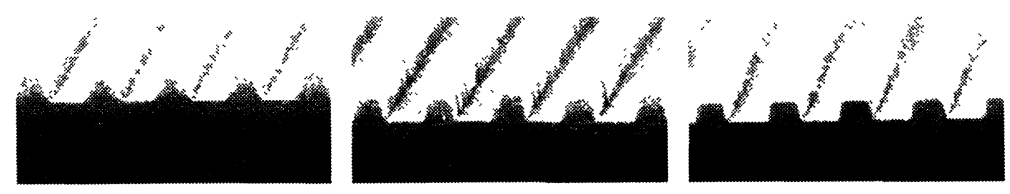

(b) F-resist B
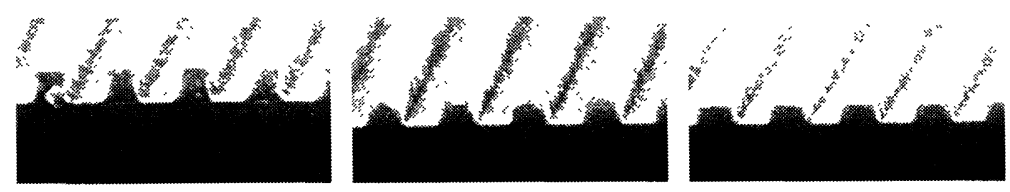

(c) F-resist C

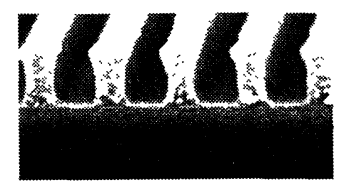

(d) KrF-resist

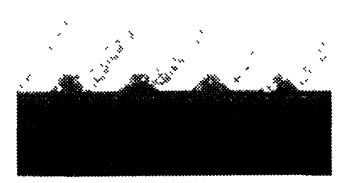

after development
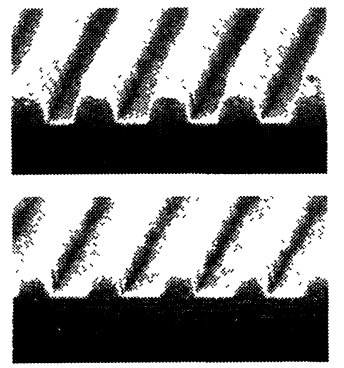

after

BARC / SiN RIE
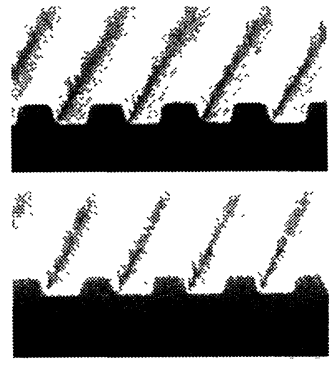

after ashing

Fig. 9. Pattern profile of 130-nm 1:1 L/S for DUV42 $(30 \mathrm{~nm}) / \mathrm{SiN}(70 \mathrm{~nm}) /$ Si substrate $(0.60-\mathrm{NA}$ microstepper using an alt-PSM, and $\mathrm{CF}_{4} / \mathrm{O}_{2} / \mathrm{Ar}$ gas).

(a) F-resist A

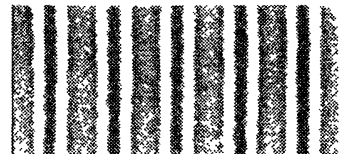

(b) F-resist B

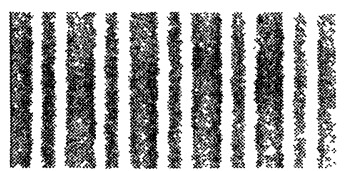

(c) F-resist C

(d) KrF-resist

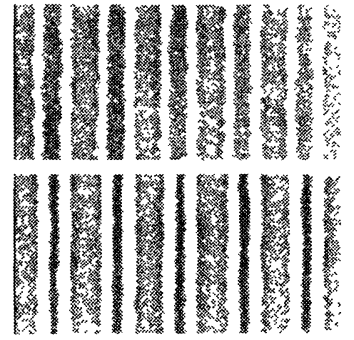

after

development
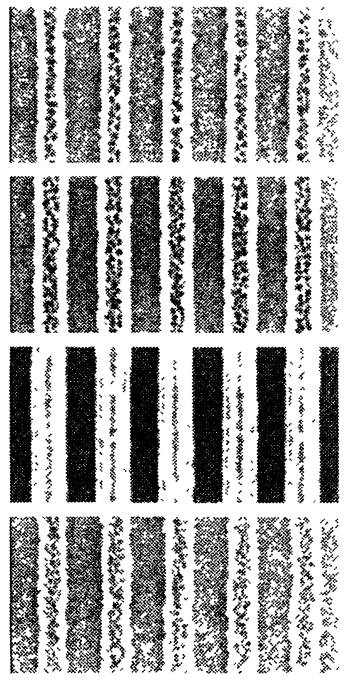

after

BARC / SiN RIE
$\operatorname{LER}(3 \sigma)$

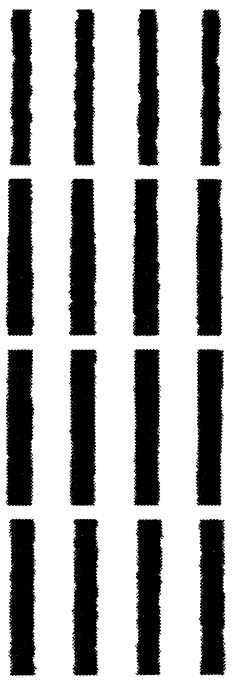

$5.3 \mathrm{~nm}$

$4.5 \mathrm{~nm}$

$3.1 \mathrm{~nm}$

$5.1 \mathrm{~nm}$

ashing

Fig. 10. Top-down SEM images of 130-nm 1:1 L/S for DUV42 (30 nm) / SiN (70 nm) / Si substrate (0.60-NA microstepper using an alt-PSM, $\mathrm{CF}_{4} / \mathrm{O}_{2} / \mathrm{Ar}$ gas). 
Table 3. Summary of etching evaluation for each resist.

\begin{tabular}{cccccc}
\hline Sample & Initial thickness & $\begin{array}{c}\text { Remaining } \\
\text { thickness } \\
(\text { BARC loss }) \\
(\mathrm{nm})\end{array}$ & $\begin{array}{c}\text { RIE rate } \\
(\text { vs KrF-resist }) \\
(\mathrm{nm} / \mathrm{min})\end{array}$ & $\begin{array}{c}\text { Blanket RIE rate } \\
(\text { vs KrF-resist }) \\
(\mathrm{nm} / \mathrm{min})\end{array}$ & $\begin{array}{c}\text { LER } \\
(3 \sigma) \\
(\mathrm{nm})\end{array}$ \\
\hline F-resist A & 109.3 & 6.8 & $361.8(1.37)$ & $381.3(1.31)$ & 5.3 \\
F-resist B & 137.8 & 10.2 & $450.4(1.70)$ & $451.9(1.55)$ & 4.5 \\
F-resist C & 242.0 & 99.8 & $501.9(1.90)$ & $549.0(1.88)$ & 3.1 \\
KrF-resist & 71.7 & $0(-4.2)$ & $264.7(1.00)$ & $292.1(1.00)$ & 5.1 \\
\hline
\end{tabular}

alt-PSM, (b) shows the results of BARC / HM RIE under the optimized condition, and (c) shows the results obtained after resist ashing. The $\mathrm{KrF}$-resist showed a tapered profile because of its low transmittance $(\sim 30 \%)$, while the others showed a good rectangular profile. The RIE time was fixed at $17 \mathrm{sec}$ for all the resists. This was just enough time to complete BARC / HM RIE. The remaining thickness after RIE was $6.8 \mathrm{~nm}$ for F-resist A, 10.2 $\mathrm{nm}$ for F-resist B, $99.8 \mathrm{~nm}$ for F-resist C, and $0 \mathrm{~nm}$ for KrF-resist. Slimming of the resist pattern after RIE was observed only in F-resist C. It may have been due to the low RIE durability of F-resist C. However, the pattern profiles of the SiN HM after RIE were fairly good using any of the resists. In addition, there was no residue after BARC / resist ashing.

\subsubsection{Line edge roughness}

Top-down images of the resists are shown in Fig. 10. We measured the line edge roughness (LER, $3 \sigma$ ) after ashing. The LER of F-resist A and $\mathrm{KrF}$-resist was relatively large at $5.3 \mathrm{~nm}$ and $5.1 \mathrm{~nm}$, respectively, compared to that of F-resist B $(4.5 \mathrm{~nm})$. The LER of F-resist $\mathrm{C}$ was the best (3.1 $\mathrm{nm})$ of the four resists. There are two possible reasons for this: (1) it is due to the tapered profile and the footing at the bottom of the resist, and (2), the inhomogeneous etching durability (shown in Fig. 8) may also have an effect on LER.

\subsubsection{RIE selectivity}

Table 3 summarizes the RIE evaluation results for each resist. The initial and remaining thicknesses were measured using cross-sectional SEM images. The RIE rate obtained for the patterning results and the blanket RIE rate are also summarized in Table 3 . Note that the RIE rate calculated from the patterning results for the KrF-resist was corrected by using the blanket RIE rate of BARC. The patterning results agreed well with the blanket RIE rate.

\subsubsection{Target property}

All of the fluorine-containing resists were applicable to the optimized SiN (70-nm thick) HM process. However, the remaining thickness after RIE was insufficient for mass-production of semiconductor devices. We assume that more than $50 \%$ of the initial thickness should remain immediately after completion of the BARC / SiN RIE. Supposing that the initial resist thickness is $200 \mathrm{~nm}$ to prevent a pattern collapse, and more than $60 \%$ transmittance is required to obtain a high resolution (equivalent to $\mathrm{F}$-resist $\mathrm{C}$ ), the relative $\mathrm{RIE}$ rate (vs. KrF resist) should be less than 1.2 and the absorption coefficient should be less than $1.1(/ \mu \mathrm{m})$. To achieve this, we have to overcome the trade-off between RIE durability and transparency. This will require further improvements in resist materials, and optimization of the resist process and etching conditions. The target properties for a $157-\mathrm{nm}$ resist at various thicknesses and transmittance levels (T) are summarized in Table 4.

Table 4. Target properties for $157-\mathrm{nm}$ resists for the optimized RIE condition in a BARC (30 nm) / SiN (70 nm) structure.

\begin{tabular}{ccccc}
\hline \multirow{2}{*}{$\begin{array}{c}\text { Thickness } \\
(\mathrm{nm})\end{array}$} & Relative & \multicolumn{3}{l}{ Absorption $(/ \mu \mathrm{m})$} \\
& RIE rate & $\mathrm{T}=50 \%$ & $\mathrm{~T}=60 \%$ & $\mathrm{~T}=70 \%$ \\
& $($ vs KrF) & & & \\
\hline 150 & $<0.9$ & 2.0 & 1.5 & 1.0 \\
200 & $<1.2$ & 1.5 & 1.1 & 0.8 \\
250 & $<1.5$ & 1.2 & 0.9 & 0.6 \\
\hline
\end{tabular}

\subsection{Gate and $\mathrm{C} / \mathrm{H}$ fabrication}

We fabricated the gate pattern using the optimized HM RIE conditions. The structure was F-resist A (120 nm) / DUV42 (30 nm) / SiN (70 $\mathrm{nm}) / \mathrm{WSi}(50 \mathrm{~nm}) /$ poly-Si $(50 \mathrm{~nm}) / \mathrm{SiO}_{2}(100$ $\mathrm{nm}$ ) / Si substrate. Figure 11 (a) shows 100-80 nm resist patterns delineated using a 0.60-NA microstepper and an alt-PSM, (b) shows the results 
100-nm1:1L/S

(a)

(b)

$$
\begin{gathered}
\text { after } \\
\text { BARC/SiN RIE }
\end{gathered}
$$

(c)

after
resist/BARC ashing

(d) WSi / poly-Si RIE
85-nm1:1L/S
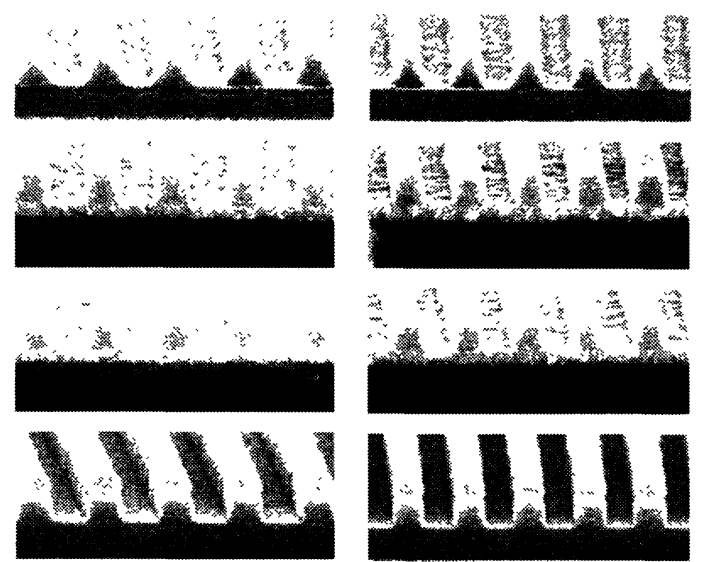

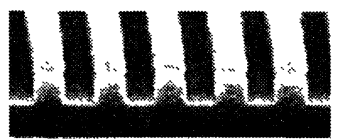

80-nm1:1L/S
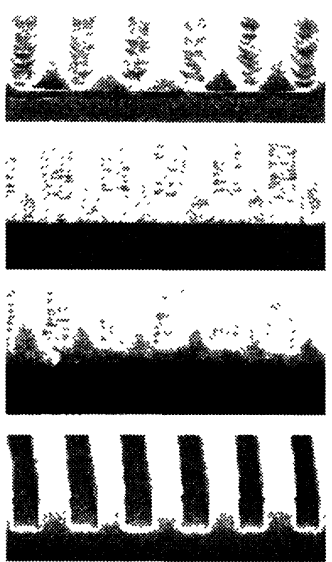

Fig. 11. Pattern profile of F-resist A $(120 \mathrm{~nm}) / \mathrm{DUV} 42(30 \mathrm{~nm}) / \mathrm{SiN}(70 \mathrm{~nm}) / \mathrm{WSi}(50 \mathrm{~nm}) / \mathrm{poly}-\mathrm{Si}(50 \mathrm{~nm}) / \mathrm{SiO} 2$ $(100 \mathrm{~nm}) / \mathrm{Si}$ structure (exposure tool was a 0.60-NA microstepper using an alt-PSM. Feature size was 100, 85, or 80-nm 1:1 L/S).
75-nm1:1L/S
70-nm1:1L/S
65-nm1:1L/S
(a) development

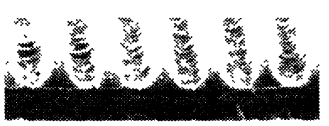
(b)
after
BARC / SiN RIE
(c) $\begin{gathered}\text { after } \\ \text { resist / BARC ashing }\end{gathered}$
(d) WSi / poly-Si RIE
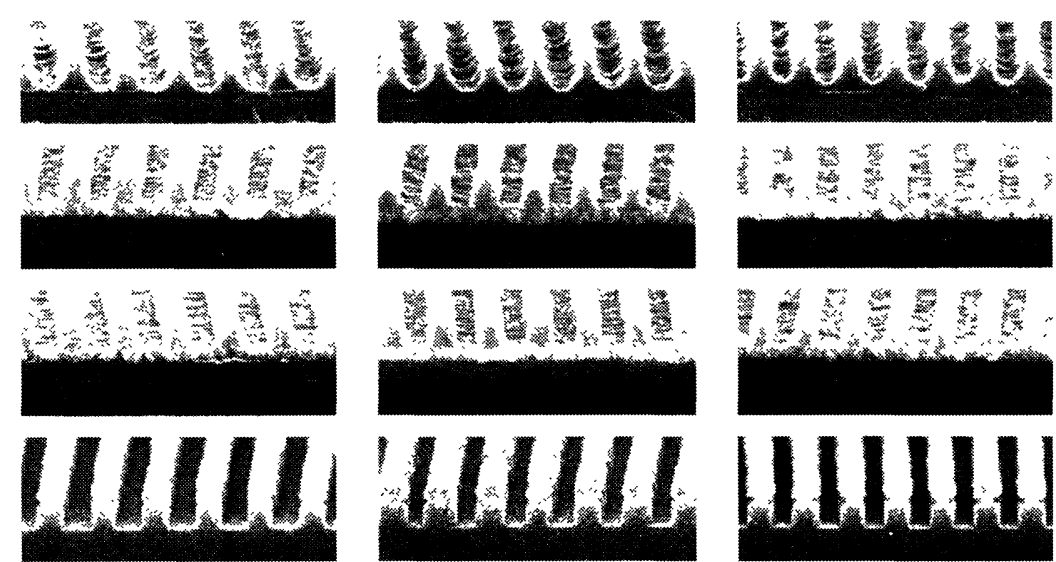

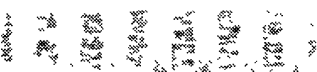

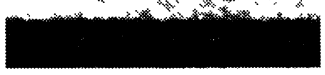

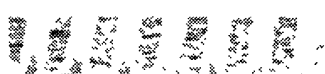

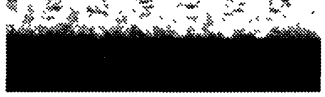
1. I.

Fig. 12. Pattern profile of F-resist A $(120 \mathrm{~nm}) / \mathrm{DUV} 42(30 \mathrm{~nm}) / \mathrm{SiN}(70 \mathrm{~nm}) / \mathrm{WSi}(50 \mathrm{~nm}) / \mathrm{poly}-\mathrm{Si}(50 \mathrm{~nm}) / \mathrm{SiO}{ }_{2}$ $(100 \mathrm{~nm}) / \mathrm{Si}$ structure (exposure tool was a 0.85 -NA microstepper using an alt-PSM. Feature size was 75, 70, or 65-nm $1: 1 \mathrm{~L} / \mathrm{S})$.

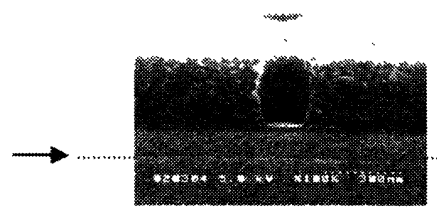

(a)

after development

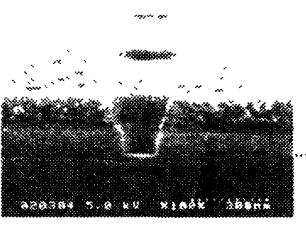

(b)

after BARC / SiN RIE

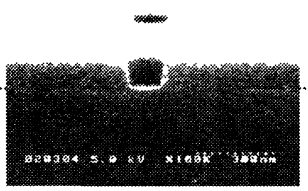

(c)

after resist / BARC ashing

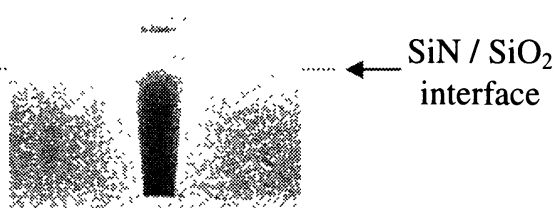

(d)

after

TEOS-SiO 2 RIE

Fig. 13. Pattern profile of F-resist C $(250 \mathrm{~nm}) / \mathrm{DUV} 42(30 \mathrm{~nm}) / \mathrm{SiN}(100 \mathrm{~nm}) / \mathrm{TEOS}-\mathrm{SiO}_{2}(500 \mathrm{~nm}) / \mathrm{Si}$ substrate (exposure tool was a 0.60-NA microstepper using a 5\% att-PSM. Feature size was $150-\mathrm{nm} \mathrm{C} / \mathrm{H}$ ). 
of BARC / SiN RIE, (c) shows the results after resist ashing, and (d) shows the results of WSi / poly-Si $\mathrm{RIE}\left(\mathrm{Cl}_{2} / \mathrm{HBr}\right.$ gas). We succeeded in fabricating an 80-nm gate pattern (the $\mathrm{k} 1$ factor of the Rayleigh equation is equal to 0.31). Figure 12 shows the results of gate fabrication using a 0.85-NA microstepper and an alt-PSM. The 65-nm gate patterns were successfully fabricated $(\mathrm{k} 1=0.35)$. The pattern pitch was only $130 \mathrm{~nm}$.

Next, we applied the optimized HM process to $\mathrm{C} / \mathrm{H}$ fabrication. The structure was $\mathrm{F}$-resist $\mathrm{C}$ $(250 \mathrm{~nm}) / \operatorname{DUV} 42(30 \mathrm{~nm}) / \mathrm{SiN}(100 \mathrm{~nm}) /$ TEOS- $\mathrm{SiO}_{2}(500 \mathrm{~nm}) / \mathrm{Si}$ substrate. Figure 13 (a) shows the resist pattern after development exposed with a $0.60-\mathrm{NA}$ microstepper using a 5\% att-PSM, (b) shows the result of BARC / SiN RIE (under the optimized conditions), (c) shows the results after BARC / resist ashing, and (d) shows the results of TEOS-SiO ${ }_{2} \mathrm{RIE}\left(\mathrm{C}_{4} \mathrm{~F}_{6} / \mathrm{Ar} / \mathrm{O}_{2}\right.$ gas $)$. The remaining resist thickness after BARC / SiN RIE was about $120 \mathrm{~nm}$. F-resist $\mathrm{C}$ and DUV42 were clearly removed by ashing. We then obtained a $150-\mathrm{nm} \mathrm{C} / \mathrm{H}$ pattern with a good profile.

\section{Conclusions}

We have described a hard mask process suitable for 157-nm lithography. Using a BARC $(30 \mathrm{~nm}) / \mathrm{SiN}(70 \mathrm{~nm})$ structure, we fabricated a WSi / poly-Si $65-\mathrm{nm}$ gate pattern with a $0.85-\mathrm{NA}$ microstepper and a TEOS-SiO2 150-nm C/H pattern with a 0.60-NA microstepper. This clearly demonstrates that our HM process is the leading candidate for sub-70nm-node semiconductor devices.

\section{Acknowledgements}

We would like to thank Dr. L. H. Chen and K. Inazawa (Tokyo Electron AT Ltd.) for the RIE evaluation, and O. Yamabe, N. Kanda, J. H. Kim, and T. Suganaga (Selete) for their help with the 157-nm patterning. We also thank Dr. N. Endo and W. Wakamiya (Selete) for their guidance and encouragement.

\section{References}

1. R. R. Kunz, T. M. Bloomstein, D. E. Hardy, R. B. Goodman, D. K. Downs, and J. E. Curtin, Proc. SPIE, 3678 (1999), 13.
2. K. Patterson, M. Yamachika, R. Hung, C. Brodsky, S. Yamada, M. Somervell, B. Osborn, D. Hall, G. Dukovic, J. Byers, W. Conley, and C.G. Willson, Proc. SPIE, 3999 (2000), 365.

3. D. Schmaljohann, Y. C. Bae, G. L. Weibel, A. H. Hamad, and C. K. Ober, Proc. SPIE, 3999 (2000), 330.

4. M. K. Crawford, A. E. Feiring, J. Feldman, R. H. French, M. Periyasamy, F. L. Schadt III, R. J. Smalley, F. C. Zumsteg, R. R. Kunz, V. Rao, L. Liao, and S. M. Holl, Proc. SPIE, 3999 (2000), 357.

5. M. K. Crawford, A. E. Feiring, J. Feldman, R. H. French, V. A. Petrov, , F. L. Schadt III, R. J. Smalley, and F. C. Zumsteg, Proc. SPIE, 4345 (2001), 428.

6. R. R. Dammel, R. Sakamuri, A. Romano, R. Vicari, C. Hacker, W. Conley, and D. Miller, Proc. SPIE, 4345 (2001), 350.

7. H. Ito, G. M. Wallraff, P. Brock, N. Fender, H. Truong, G. Breyta, D. C. Miller, M. H. Sherwood, and R. D. Allen, Proc. SPIE, 4345 (2001), 273.

8. T. H. Fedynyshyn, R. R. Kunz, R. F. Sinta, M. Sworin, W. A. Mowers, R. B. Goodman, and S. P. Doran, Proc. SPIE, 4345 (2001), 296.

9. N. Shida, H. Watanabe, T. Yamazaki, S. Ishikawa, M.Toriumi, and T. Itani, Proc. SPIE, 4690 (2002), in press.

10. M.Toriumi, N. Shida, H. Watanabe, T. Yamazaki, S. Ishikawa, and T. Itani, Proc. SPIE, 4690 (2002), in press.

11. W. D. Domke, V. L. Graffenberg, S. Patel, G. K. Rich, H. B. Cao, and P. F. Nealey, Proc. SPIE, 3999 (2000), 313.

12. K. R. Dean, C. V. Peski, H. S. Kim, S. Hien, D. C. Owe-Yang, and W. Conley, J. Photopolym. Sci. Technol., 14 (2001), 573.

13. S. Miyoshi, T. Furukawa, H. Watanabe, S. Irie, and T. Itani, Proc. SPIE, 4690 (2002), in press.

14. T. Suganaga, N. Kanda, O. Yamabe, K. Watanabe, S. Miyoshi, T. Furukawa, and T. Itani, Proc. SPIE, 4691 (2002), in press.

15. S. Mori, K. Adachi, T. Fukushima, and Y. Sato, J. Photopolym. Sci. Technol., 9 (1996), 601.

16. R. Yamanaka, T. Mine, T. Tanaka, and T. Terasawa, Jpn. J. Appl. Phys., 36 (1997), 7620. 